\title{
Data Collection for the Assessment of Aquatic Communities in Northeastern Wyoming and Southeastern Montana, 2005
}

\section{Introduction}

This fact sheet describes data collection for the assessment of aquatic communities in northeastern Wyoming and southeastern Montana. This assessment was conducted in 2005 in cooperation with the Bureau of Land Management (BLM), Montana Department of Environmental Quality (MDEQ), Montana Fish, Wildlife and Parks (MFWP), U.S. Environmental Protection Agency (USEPA), Wyoming Department of Environmental Quality (WDEQ), and Wyoming Game and Fish Department (WGFD). This fact sheet also describes groups with interests or responsibilities in monitoring the effects of coal-bed natural gas development within the Powder River Basin.

The Powder River Structural Basin (PRB) in northeastern Wyoming and southeastern Montana is an important source of energy resources for the United States. Resources produced from the basin include coal, oil, uranium, conventional natural gas, and within the last decade coal-bed natural gas (CBNG) that often is referred to as coal-bed methane. As of 2004, more than 10,000 CBNG wells had been drilled in northeastern Wyoming (Wyoming Oil and Gas Conservation Commission, 2005). An estimated 50,000 to 60,000 CBNG wells could be drilled and put into production in the PRB by 2012 (Wyoming Oil and Gas Conservation Commission, 2005). Throughout the PRB large volumes of ground water are removed from coal-bed aquifers and discharged on the surface in order to recover CBNG. This ground water, which can be slightly to moderately saline, is discharged to perennial, intermittent, and ephemeral streams and to surface impoundments. It is currently unknown what potential effects these discharges will have on aquatic communities (fish, macroinvertebrates, and algae) and their habitats.

\section{Powder River Natural Gas Interagency Working Group}

Over a million acres within the PRB are public lands managed by the BLM. Development of mineral resources on public lands requires leases and permits from the BLM along with permits, approvals, and reviews by several other Federal and State agencies. CBNG development in the PRB is affecting agencies involved in permitting and monitoring in two States and two Tribes. To enhance coordination among interested agencies and reduce duplication of effort, the BLM organized the Powder River Natural Gas Interagency Working Group (PRB IWG). The PRB IWG charter states that it "was established as the forum for government agencies to address, discuss,

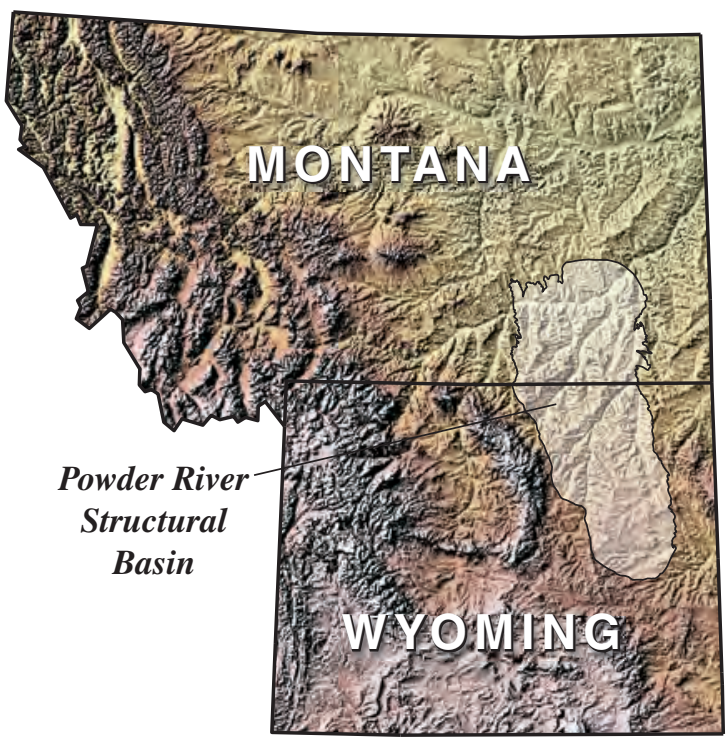

and find solutions to issues of common concern to all parties involved in permitting and monitoring of CBNG development" (Powder River Natural Gas Interagency Working Group, 2004). Led by the BLM, the PRB IWG is composed of managers and technical staff from local, State, Tribal, and Federal government agencies with land management, conservation, or regulatory responsibilities in the PRB, as well as agencies like the U.S. Geological Survey (USGS) that provide technical support.

The vision of the PRB IWG is to provide for development of natural gas resources while protecting the cultural and natural resources of the PRB. The mission of the PRB IWG is to (1) provide for environmentally sound energy development, (2) develop coordinated and complementary best management practices, guidelines, and programs related to CBNG activities to conserve and protect resources, (3) monitor the impact of CBNG activities and assess the effectiveness of mitigating measures, (4) develop and integrate databases and scientific studies needed for effective resource management and planning, and (5) promote compatibility in the application of each agency's mission.

In order to effectively address the technical issues presented by CBNG development, task groups that are staffed by technical specialists from the member agencies of the PRB IWG were formed to address specific resource issues (Clark and others, 2005). The task groups include air, aquatics, water, and wildlife. 

vill make recommendations of measures to mititiate CBNG dvelopment effects and methods to assess the effectivenes the meaures.
Che ATG developed an aquatic-biota monitoring plan that
describes monitoring of aquatic bitata and their habitat for drain-

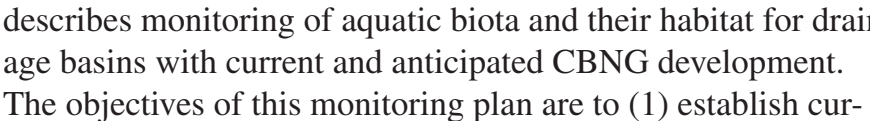
ent conditions for aquatic biota and their habitat and (2) deleron aquatic life. Atthough it is too late to establish a true baseline of aquitic crimunities and habitapt can be ascurent condition Sampling to assess the current (2005) condition of aquatic The BLM, MDEQ, MFWP, USEPA, WDEQ, and WGFD. A otal of 47 sties were sampled (fig. I). The scope of work varied from Wyoming (26 sites) and Montana (21 sites) as shown in
whle 1 .
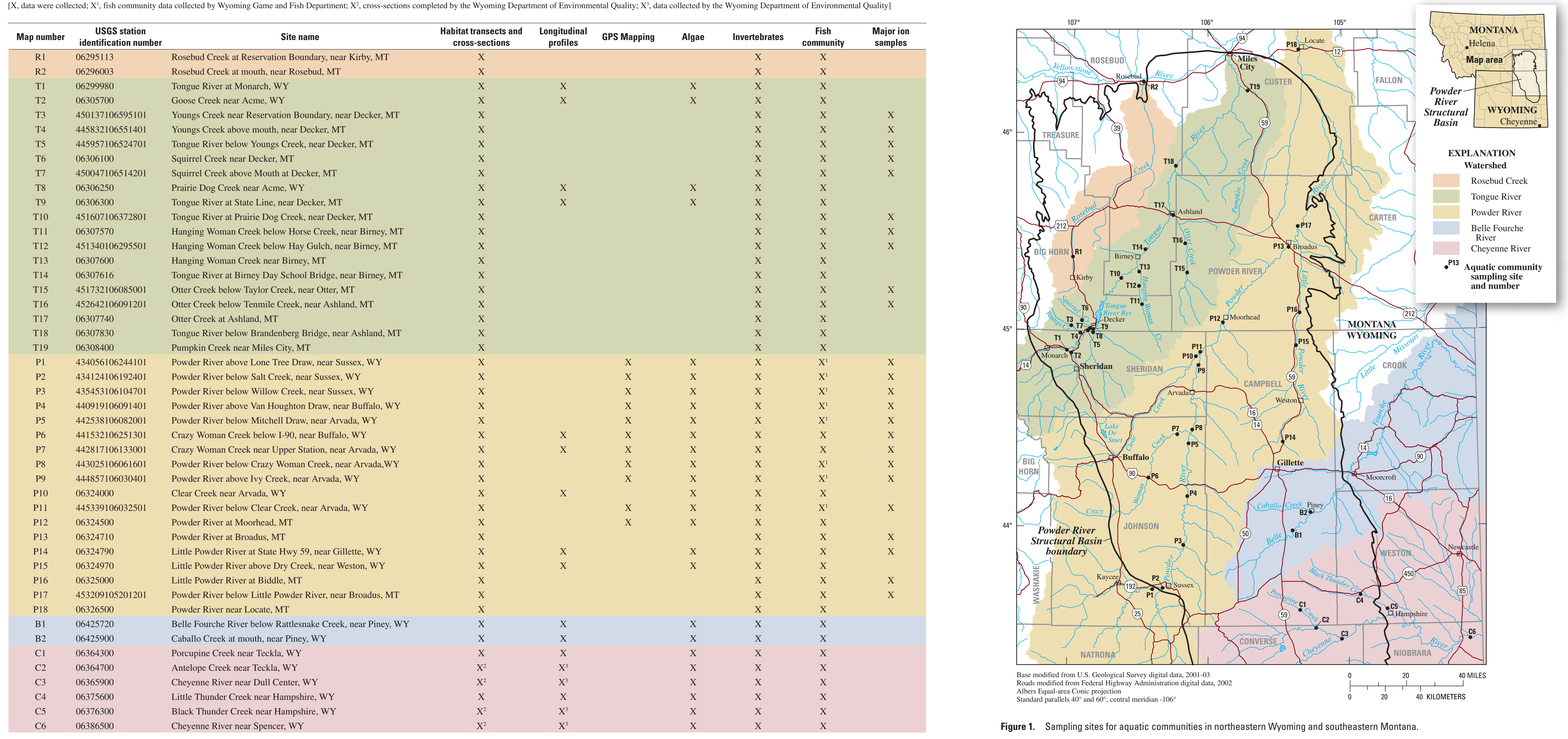

Figure 1. Sampling sites for a quatic communities in northeastern Wyoming and southeastern Montana. 
ong-term reference. A 100-particle pebble count was completed at least one riffle cross section and one pool cross section Worman, 1954). At Montana sites, two to four cross sections were moniten and surveyed when possible, however, longHeriles and pebble counts were not done.

Hiver at data collection varied between the main stem Powder River and all other streams sampled (table 1). The Powder River was sampled differently than the other streams due to it continuously shifting sand habitats. The WGFD established 2-mile study reaches on the main stem Powder River in Wyoming during 2004. WGD and USGS personnel coordinated field efforts and jointly sampled sites on the mainstem Powder mapping was conducted in the spring of the year (pre-runits and during low-flow conditions in July. WGFD (per-ruof) lected fish samps and made warm-water strem assessments during both sampling periods following WGFD protocols (Dave Zaft Wyoming Game and Fish Denertment, written com (Dave 2005). USGS personnel provided high-resolution global-positioning system mapping of mesohabitat types (riffle, run, shoil pool, and isolated backwater) for both periods. During low-flow sampling of Powder River sites in Wyoming, habitat sampling was performed by USGS personnel using a modified version the EMAP and Harrelson and others (1994) protocols. USGS personnel also collected samples for algae and benthic macroinvertebrates. Along the main stem Powder River in Montana, USGS personnel used WGFD protocols to determine sampling reaches and assess fish populations. Stream-habitat transects along the main stem Powder River were sampled in the sam manner in both Wyoming and Montana. A transect was set across each habitat sampled for fish, and applicable feature along each of these transects were recorded following the EMAP protoco

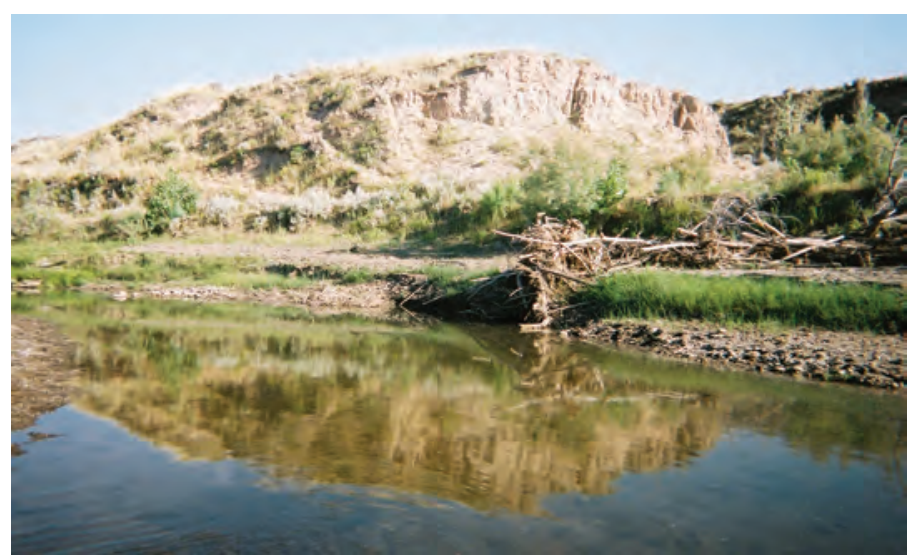

Powder River above Lone Tree Draw, near Sussex, Wyoming (site P1)

Benthic macroinvertebrates were collected at each of the 47 sites (table 1) following NAWQA protocols (Moulton and others, 2002). At sites where riffles were available in the strean reach, riffles were sampled as the richest targeted habitat (RTH). Each RTH sample was a composite, semi-quantitative sample from five points, with a total sampled area of 1.25 square meters. About 75 percent of the ATG sites sampled in 2005 had riffles and RTH samples. A qualitaive nuli-habitat (QMH)

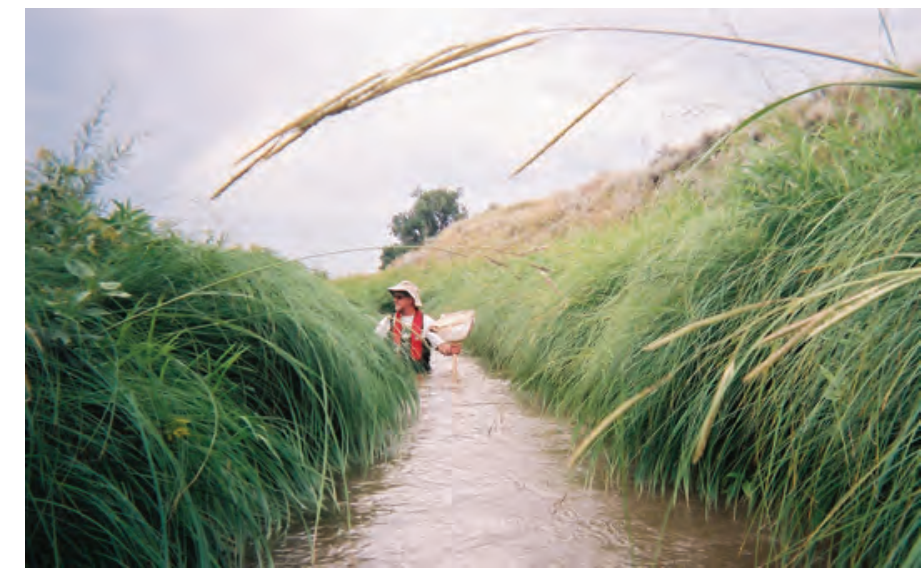
Invertebrate sampling at Prairie Dog Creek near Acme, Wyoming (site T\&

tioned as the primary sample at sites where riffles were absent. The QMH sample was a timed collection (1 hour) of macroinvertebrates from the various microhabitats in the reach, such as logs, macrophytes, and soft substrates. The macroinvertebrate samples were sent to Utah State University for taxonomic analysis.

Algae samples were collected at 24 sites in Wyoming and 2 sites in Montana near the State line (table 1). At each site where riffles were available, semi-quantitative samples of periphytic algae were scraped from 25 rocks and composited into a RTH sample following NAWQA protocols (Moulton and others, 2002). At sites without riffles, periphyton samples were collected from depositional targeted habitat (DTH) in the euphotic zone of pools. A subsample of the RTH algae samples was frozen on dry ice and sent to the USGS National Water Quality Laboratory for analysis of chlorophyll- $a$ and ash-free dry mass. The RTH and DTH algae samples were sent to a laboratory for taxonomic analysis following procedures described by Charles

Fish communities were sampled at each site from a reach length of 40 mean-wetted-channel widths following EMAP proPock (Peck and ohes, 2003) with hie exception of sites on the

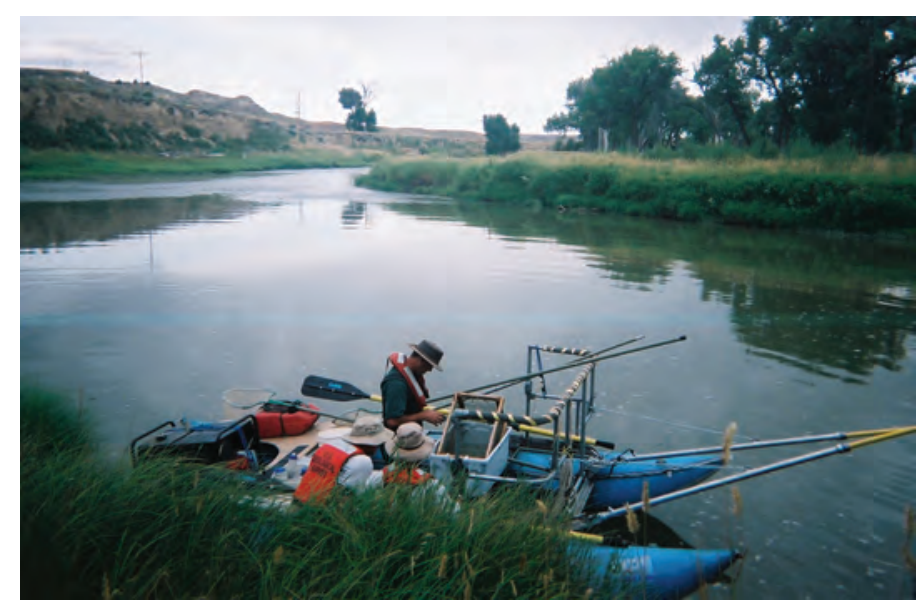
Fish community sampling at Tongue River at State line near Decker, Montan
(site To) (photograph by Mike Sweat) were collected by seining, although sites on the main stem of the Tongue River and some of the tributaries to the Tongue River were sampled by electrofishing. Fish generally were released back to the stream after sampling, but voucher specimens of a few fish were retained for taxonomic confirmation and identification of unknown or difficult-to-identify specimen A quality-assurance plan for fish taxonomy was developed for this project.

\section{Data Availability}

Additional information about the ATG project, including he data collected to date are available at URL: http://wy.water usgs.gov/projects/atg/. Data which are currently available include chlorophyll- $a$ and ash-free dry mass concentrations in algae samples and major-ion concentrations in water samples itloces cor is not currently molored (table 1) as part of the Water Group's surfece-water monitoring progra. All water-qulity data collected by the USGS, including major-ion dota collected as part of the monitoring plan are stored electronically in the USGS National Water Information System and are available URL: http://waterdata.usgs. gov/nwis/. More information abou the PRB IWG and Task Group activities is available at URL: http://www.wy.blm.gov/bfo/prbgroup/index.htm.

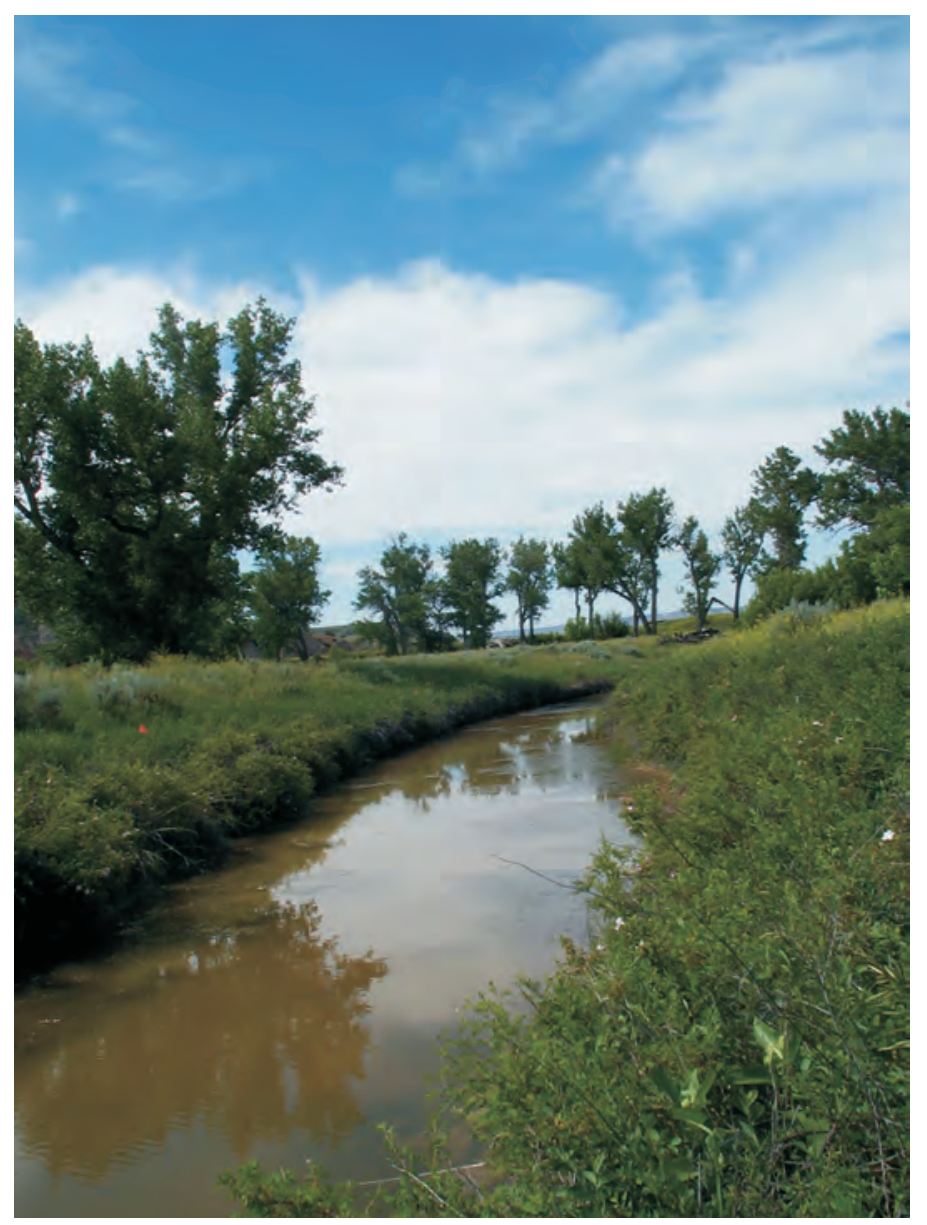

Hanging Woman Creek near Birney, Montana (site T13) (photograph by Stacey Kinsey)
References

Charles, D.F., Knowles, Candia, and Davis, R.S., 2002, Protocols for the analysis of algal samples collected as part of the U.S. Geological Survey National Water-Quality Assessment Patrick Center for Environmental Research —Phycology Section, Report 02-06, 124 p.

Clark, M.L., Lambing, J.H., and Bobst, A.L., 2005, Surfacewater monitoring in watersheds of the Powder River Basin 2005: U.S. Geological Survey Fact Sheet 2005-3137, 4 p. [Available online at http://pubs.water.usgs.gov/fs2005-3137/]

Harrelson, C.C., Rawlins, C.L., and Potyondy, J.P., 1994, Stream channel reference sites - an illustrated guide to field technique: Fort Collins, Colo., U.S. Department of Agri-
culture, Forest Service, Rocky Mountain Forest and Rang Experimentation Station, General Technical Report RM-245, $61 \mathrm{p}$.

Moulton, S.R. II, Kennen, J.G., Goldstein, R.M., and Hambrook, J.A., 2002, Revised protocols for sampling algal, Water-Quality Assessment Program: U.S. Geol National Open-File Report 02-150, 75 p.

Peck, D.V., Lazorchak, J.M., and Klemm, D.J., eds., 2003, Environmental Monitoring and Assessment Program -

surface waters: Western Pilot Study field operations manual for wadeable streams: Washington, D.C., U.S. Environmental Protection Agency, 258 p.

Powder River Natural Gas Interagency Working Group, 2004 Charter: Buffalo, Wyo., Bureau of Land Management,

Wolman, M.G., 1954, A method of sampling coarse river bed Union, v. 35 [no. 6], p. 951-956.

Wyoming Oil and Gas Conservation Commission, 2005, digita data, accessed Dec. 8, 2005, at http://wogcc.state.wy.us/ coalbedchart.cfm

By Peter R. Wright, David A. Peterson, and Laura L. Hallber Layout and graphics by Suzanne C. Roberts

For more information, contact:

Director

U.S. Geological Survey

Wyoming Water Science Center

Cheyenne, Wyoming 82001

(307) $778-2931$

http://wy.water.usgs.go 